JIOM Nepal. Volume 41 Number 3. December 2019, page 30-34.

\title{
Changes in the Quality of Life of Outpatients in Methadone Maintenance Treatment Clinics in Kathmandu Valley
}

\author{
Basanta Sapkota ${ }^{1}$, Pratikchya Tulachan ${ }^{2}$, Saroj P Ojha ${ }^{2}$, Manisha Chapagai ${ }^{2}$, Saraswati Dhungana ${ }^{2}$ \\ ${ }^{1}$ Gan Regional Hospital, Ministry of Health, Maldives, ${ }^{2}$ Department of Psychiatry and Mental Health, Maharajgunj \\ Medical Campus, Tribhuvan University Teaching Hospital, Maharajgunj, Kathmandu, Nepal
}

\section{Corresponding author:}

Basanta Sapkota, MBBS, MD

Gan Regional Hospital, Ministry of Health, Maldives

Email: basantasapkota1970@gmail.com

Submitted : September 2, 2019

Accepted : November 30, 2019

\begin{abstract}
Introduction

Methadone maintenance treatment (MMT) is widely accepted treatment option for the opioid dependent individuals. The evaluation of the quality of life represents the assessment of the effectiveness of the treatment program. The study aimed to explore the impact of MMT program on clients' quality of life in the first 6 months of treatment.
\end{abstract}

\section{Methods}

A total of 63 patients were recruited from the 5 different methadone clinics of Kathmandu valley. A prospective follow-up design was used. The semi-structured pro forma was filled up. To assess quality of life, WHO Quality of Life questionnaire (WHOQOL-BREF, 26-item version) was used. The tool was used to assess the quality of life at the baseline and after 6 months of enrollment in MMT program.

\section{Results}

Following 6 months of methadone maintenance treatment of opioid dependent individuals, significant improvements $(P<0.001)$ were observed in all measured domains of quality of life i.e. physical, psychological, environmental and social. The least improvement was noted in the social domain.

\section{Conclusion}

Methadone maintenance treatment is helpful in improving the quality of the life of the opioid dependent individuals in MMT clinics.

Keywords: Kathmandu valley, methadone, methadone maintenance treatment, quality of life

\section{INTRODUCTION}

S ubstance abuse is a global problem that negatively impacts the health, social and economic structure of the individuals, families, communities, and nations. According to the 2018 World Drug Report of the United Nations Office of Drugs and Crime (UNODC), it is estimated that 1 in 18 adults, or a quarter of a billion people between the ages of 15 and 64 years, used at least one drug in 2016. ${ }^{1}$ Among them 30.5 million people worldwide suffer from drug use disorder (harmful use or drug dependence). The report also highlighted that 34.3 million misused opioid in 2016, which is 1.3 million more than in 2014. Similarly, Nepal has also recorded the growth of Opioid users from 46,310 in 2006 to 91,534 in 2009. ${ }^{2}$

Opioid dependence is the major public health concern which is associated with high morbidity and mortality. Staphylococcal pneumonitis, endocarditis, meningitis, brain abscess, viral hepatitis particularly B and C, malaria, tetanus, osteomyelitis, syphilis and HIV are frequent complications due to intravenous injection which is the most common means of drug use in opioid dependents. ${ }^{3}$ To mitigate this problem, 
Dole and Nyswander started the Methadone clinics in the 1960s which became models for the Methadone Maintenance Treatment (MMT) program throughout the world. ${ }^{4}$ In Nepal, the first MMT clinic was introduced in a psychiatric hospital in Kathmandu in 1994. Since then methadone maintenance clinics has been expanded and in Kathmandu valley alone there are five methadone maintenance clinics where hundreds of opioid dependent individuals receive treatment each day.

Since its introduction, MMT has become the most popular and extensively researched methods for the treatment of opioid dependence worldwide. Studies have consistently found that the enrollment in the MMT program is associated with the reduction in the use of illicit drugs, risky injecting and the sharing of injecting equipment and improvement of the overall heath and reduction of mortality of the opioid dependent individuals. ${ }^{5-7}$

Measurement of changes in the quality of life of Opioid dependent individuals has been increasingly used as a yardstick of effectiveness of MMT program. The numerous published studies including a systematic review by Feelemyer et al. (2014) in the field of quality of life have consistently shown that MMT program is associated with the improvement of quality of life of opioid users within the short period of time (3-6 months). ${ }^{7-9}$ However, despite MMT clinics are being operated in Nepal for more than a decade, study regarding the effectiveness of this program is sparse. Study of effectiveness of MMT Program in Nepalese context may help to know whether this MMT program is benefiting the clients receiving the service from the Methadone clinics or not. So, this study was carried to find out the changes in quality of life of outpatients in MMT program in Kathmandu valley in the first 6 months of treatment.

\section{METHODS}

This prospective follow up study was conducted in three districts of Kathmandu valley. A total of 63 patients were selected by purposive sampling method from the clients visiting in the five MMT clinics of Kathmandu valley. The study period was from May 2016 to October 2016 (6 months). The inclusion criteria were all opioid dependent persons (aged 18-65) who were newly enrolled in the outpatient methadone maintenance program and were willing to undergo follow-up assessment at 6 months. Those with co-morbid psychiatric disorders such as schizophrenia, delusional disorder, other anxiety disorders and mood disorders were excluded. Ethical approval was taken from Institutional Review Committee of Institute of Medicine, Maharajgunj, Kathmandu.
The written informed consent was taken from each of the participants and the semi-structured pro-forma was filled by the clients themselves. The World Health Organization Quality of Life Assessment Brief Version (WHOQOL-BREF) was administered to the clients at baseline i.e. before taking the methadone. It was assisted by trained health personnel like nurses, and doctors present at MMT clinics to ensure that clients fully understood the questionnaire. Subsequent assessments were completed by the participants themselves who were still taking the methadone at the end of 6 months. During the period of study among 84 clients, 21 clients dropped out. In methadone program clients are supposed to go to MMT clinics everyday to take their methadone dose. The clients, who missed their doses for 7 consecutive days were considered as dropouts. Then available data was analyzed for change in quality of life at the end of 6 months.

Self designed semi-structured pro forma was used to collect information about socio-demographic profile and details of substance taking history and associated factors of the clients.

We used the WHOQOL-BREF, which was developed to measure overall quality of life and general health status. The WHOQOL-BREF has been translated into the Nepali language, and the translated version showed good internal reliability (Cronbach's alpha 0.85) in a study of QOL among people living with HIV/AIDS. ${ }^{10}$ WHOQOL-BREF has 26 items grouped under four domains: (i) physical health, (ii) psychological well-being, (iii) social relations, and (iv) environment. There are two other items that are measured separately: (1) patient's overall perception of $\mathrm{QOL}$, and (2) overall perception on his/her health. The WHOQOL-BREF questionnaire uses a five-point Likert scale (1-5). Participants responded to questions according to their experience in the previous two weeks. Reverse items (items 3, 4 and 26) were scored reversely. Domain scores for the WHOQOLBREF were calculated by taking the mean of all items included in each domain and multiplying by a factor of four. The original domain scores were transformed to a scale of 0-100 according to the equation in the published guidelines. A high score represents good quality of life.

Data were analyzed using SPSS Statistics version 17. Dependent t-test was used to determine the significance of the difference between the quality of life scoring at 0 and 6 months.

\section{RESULTS}

Among 63 patients who were taking methadone regularly till the end of study period of 6 months, 
Table 1. Socio demographic characteristics of clients

\begin{tabular}{|c|c|}
\hline Variables & Frequency (\%) \\
\hline $\begin{array}{l}\text { Sex } \\
\text { Male } \\
\text { Female }\end{array}$ & $\begin{array}{c}61(96.8) \\
2(3.2)\end{array}$ \\
\hline $\begin{array}{l}\text { Marital Status } \\
\text { Single } \\
\text { Married } \\
\text { Separated } \\
\text { Widowed }\end{array}$ & $\begin{aligned} 37 & (58.7) \\
21 & (33.3) \\
4 & (6.4) \\
1 & (1.6)\end{aligned}$ \\
\hline $\begin{array}{l}\text { Education } \\
\text { University } \\
\text { H.Secondary } \\
\text { Secondary } \\
\text { Primary } \\
\text { Read and write } \\
\text { Illiterate }\end{array}$ & $\begin{array}{c}10(15.9) \\
24(38.1) \\
15(23.8) \\
7(11.1) \\
5(7.9) \\
2(3.2)\end{array}$ \\
\hline $\begin{array}{l}\text { Occupation } \\
\text { Employed } \\
\text { Unemployed }\end{array}$ & $\begin{array}{l}43(68.2) \\
20(31.8)\end{array}$ \\
\hline $\begin{array}{l}\text { Family type } \\
\text { Nuclear } \\
\text { Joint } \\
\text { Broken }\end{array}$ & $\begin{array}{c}36(57.2) \\
26(41.2 \\
1(1.6)\end{array}$ \\
\hline $\begin{array}{l}\text { Past Illness } \\
\text { Yes } \\
\text { No }\end{array}$ & $\begin{array}{l}12(19.1) \\
51(80.9)\end{array}$ \\
\hline $\begin{array}{l}\text { Past drug treatment } \\
\text { Yes } \\
\text { No }\end{array}$ & $\begin{array}{l}32(50.8) \\
31(49.2)\end{array}$ \\
\hline $\begin{array}{l}\text { Type of drugs } \\
\text { Heroin only } \\
\text { Polysubstance }\end{array}$ & $\begin{array}{c}5(7.9) \\
56(92.1)\end{array}$ \\
\hline
\end{tabular}

61 of them were male and 2 were female. The age of the subjects joining the MMT program was variable and majority was from age group 25 to 30. Thity three percent of them were married and most of them (68.2\%) had full time employment. Maximum number of the subjects was educated up to higher secondary level and mostly they were from nuclear family. Socio demographic characteristics of the subjects are listed in Table 1.

Table 2 shows the changes of quality of life subscale scores of outpatients receiving MMT at baseline (before the clients started taking methadone after enrolment in MMT program) and after 6 months. Paired t-test was done on WHOQOL score at baseline and after 6 months (applied for 63 patients who remained in the treatment) for all four domains.

Physical health- The physical health subscale score increased from 28.62 at baseline to 59.62 after 6 months of MMT $(p<0.001)$,indicating that the physical health of outpatients improves after enrolment in the MMT program.

Psychological health- The score of psychological health increased significantly at the end of 6 months, from 27.84 at the beginning of treatment to 58.33 after 6 months of treatment $(p<0.001)$.

Social Relationships-The subscale score for social relationships showed the least improvement, with mean increment of 26.85 from baseline to at the end of 6 months.

Environmental health- The score for Environment domain showed mean improvement of $28.63 \pm 11.77$ within the 6 months of MMT.

\section{DISCUSSION}

This study examined the change in quality of life of the opioid dependent individuals after six months of enrolment in the MMT program in Kathmandu valley.

Our study has shown marked improvement of quality of life in all four measured domains of WHOQOL-BREF: physical health, psychological health, social relationships and environment, within 6 months of enrolment in MMT program. The findings are similar to other studies which measured the quality of life. Nordin et al. and Baharom et al. found the notable improvement of quality of life of opioid users of Malaysia in all four domains within six months of therapy. ${ }^{11,12}$ Torrens et al. had also shown significant positive change in the quality of life of the heroin addict in the first year of MMT, which continued to increase slowly but steadily in next 3 years. ${ }^{13}$ The research of Padaiga et al. concluded that enrolment in MMT program remarkably improved physical, psychological and environment health of the clients at 6 months but

Table 2. Paired t-test quality of life scores by domain at baseline and at 6 month

\begin{tabular}{lccccc}
\hline \multicolumn{1}{c}{ Domain } & $\begin{array}{c}\text { Baseline score } \\
(\text { mean } \pm \text { SD })\end{array}$ & $\begin{array}{c}6 \text { month score } \\
(\text { mean } \pm \text { SD })\end{array}$ & $\begin{array}{c}\text { Difference } \\
(\text { mean } \pm \text { SD })\end{array}$ & t-value & p-value \\
\hline Physical & $28.62 \pm 11.24$ & $59.62 \pm 10.40$ & $-31.00 \pm 12.74$ & -19.31 & $<0.001$ \\
Psychological & $27.84 \pm 11.29$ & $58.33 \pm 11.30$ & $-30.29 \pm 13.09$ & -18.49 & $<0.001$ \\
Social & $33.86 \pm 14.96$ & $60.71 \pm 14.31$ & $-26.85 \pm 18.48$ & -11.53 & $<0.001$ \\
Environment & $30.55 \pm 10.53$ & $59.18 \pm 10.40$ & $-28.63 \pm 11.77$ & -19.31 & $<0.001$ \\
\hline
\end{tabular}


not the social relationships. ${ }^{14}$ In China, Xiao et al. found that one month of therapy can cause positive impact in quality of life among MMT clients. ${ }^{15}$ Research of $\mathrm{Ha}$ in Vietnam also demonstrated that MMT brings considerable improvement of the quality of life of drug users after 6 months of treatment. ${ }^{16}$ Similarly, Ponizovsky and Grinshpoon's work found that quality of life improved within 1 month and then remained stable until the end of the program. ${ }^{17}$

From the numerous studies done earlier, including ours has concluded that enrollment in MMT program is associated with significant improvement in quality of life of opioid dependent individuals within few months of treatment. Opioid dependents often have a very chaotic lifestyle and often have lost control over their lives at the start of treatment. They enter the MMT program in miserable condition, resulting in very poor quality of life at the time of enrollment. Sticking to the program enables them to have a stable personal, social, family and financial life. In addition to it can boost their self-esteem and self-worth, eventually leading to the overall improvement in their quality of life.

We found that physical health was the most improved quality of life domain, which was followed by psychological, environment and social relationships showed the least improvement. The findings were similar to the studies of Baharom et al. in Malaysia and Padaiga et al. in Lithuania which had concluded that the average quality of life of opiate dependent individuals significantly improved in all the domains except social relationship after 6 months of MMT. ${ }^{12,14}$ Likewise, Huong et al. had also demonstrated that social relationship has the least improvement among clients in MMT program. ${ }^{11}$ Recently the 12 month follow up study done by Chou et al. in Northern Taiwan highlighted that that there was no significant improvement in social relationship in 6 months, and improvement in social relationship was significant only at 12 months. ${ }^{8}$ The cravings for the drugs and withdrawal symptoms among opioid users are often profoundly reduced when the clients get adequate dosage of methadone, which may explain the increased feelings of improvement in their physical status after entering the MMT program.

On the other hand, explanation for the least improvement for social relationship is that opioid drug users are socially stigmatized and longer period may be required for them to reintegrate into the society. Even though they are in MMT, they are often marginalized in the society, and they are often fearful to reveal their treatment status to their friends, family members and potential employers. So, it is difficult for them to regain the trust of their acquaintances which makes it hard to enhance the quality of their social relationships in relatively short period of opioid substitution therapy. This issue can be addressed if the MMT program also focused in enhancing the social and relationship skills of the clients. On a greater scale, the general people should be made aware that addiction is a disease like cancer, diabetes, heart disease and should be encouraged to integrate the opioid dependent individuals into the community like they do for the people with other illnesses.

This study has provided the small but vital evidence of effectiveness of the MMT program in the Kathmandu Valley. Nonetheless, this study is limited by the fact that it did not try to find out the factors associated with the changes in the quality of life from the baseline and the six months of the treatment. Evaluation and amendment of some modifiable factors related to poor outcome may be helpful to improve the quality of life of certain subgroups of clients in MMT program who did not show significant improvement in WHOQOL scores.

Another major limitation is that, though 21 clients dropped out from our study, we did not try to find out the factors associated with the dropout of the clients from the MMT program as knowledge of these factors would help to promote the better retention of the service users in the program.

Although our study has consolidated the conclusions of several studies that MMT program plays crucial rule in short term positive impact on service user's quality of life, some studies have found that long term effect is inconsistent. ${ }^{8}$ Habrat et al. found an unexpected reduction in quality of life after 6 months in MMT program though it was not to the prior level ${ }^{18}$, while Maeyer et al. argued that longer duration impact is still unclear. ${ }^{19}$ So, further analyses are needed to examine the long term, sustained changes in quality of life of clients in MMT.

\section{CONCLUSION}

MMT clients who completed 6 months of treatment in the outpatient clinics of the Kathmandu Valley exhibited remarkable improvement in their quality of life. In other words, Methadone maintenance treatment is significantly benefiting the opioid users in Nepal, and they should be encouraged to stay in the MMT program.

\section{ACKNOWLEDGEMENT}

We would like to thank all the staff of Methadone Maintenance Clinics of Kathmandu Valley for their 
invaluable assistance throughout the study. Also, the cooperation of all the participants is highly appreciated.

\section{CONFLICT OF INTEREST}

None declared.

\section{REFERENCES}

1. United Nations Office for Drug and Crime. World report 20182018 [Available from: https:// www.unodc.org/wdr2018/prelaunch/WDR18_ Booklet_2_GLOBAL.pdf.

2. Ministry of health. Survey Report on Current Hard Drug Users in Nepal-2069, 2069 [Available from: www.moha.gov.np/resources/ downloadResources/74.

3. Ward J, Hall W, Mattick RP. Role of maintenance treatment in opioid dependence. The Lancet. 1999;353(9148):221-6.

4. Courtwright DT. The prepared mind: Marie Nyswander, methadone maintenance, and the metabolic theory of addiction. Addiction. 1997;92(3):257-65.

5. Emmanuelli, J., \& Desenclos, J. C. (2005). Harm reduction interventions, behaviours and associated health outcomes in France, 19962003. Addiction, 100(11), 1690-1700

6. Gibson, A., Degenhardt, L., Mattick, R. P., Ali, R., White, J., \& O'Brien, S. (2008). Exposure to opioid maintenance treatment reduces long-term mortality. Addiction, 103(3), 462-468.

7. Ball JC, Ross A. The effectiveness of methadone maintenance treatment: patients, programs, services, and outcome: Springer Science \& Business Media; 2012.

8. Chou $\mathrm{Y}-\mathrm{C}$, Shih $\mathrm{S}-\mathrm{F}$, Tsai $\mathrm{W}-\mathrm{D}$, Chiang-shan $\mathrm{RL}$, $\mathrm{Xu} \mathrm{K}$, Lee TS-H. Improvement of quality of life in methadone treatment patients in northern Taiwan: a follow-up study. BMC psychiatry. 2013;13(1):190.

9. Feelemyer JP, Jarlais DCD, Arasteh K, Phillips BW, Hagan $\mathrm{H}$. Changes in quality of life (WHOQOLBREF) and addiction severity index (ASI) among participants in opioid substitution treatment (OST) in low and middle income countries: an international systematic review. Drug and alcohol dependence. 2014;134:251-8.
10. Giri S, Neupane M, Pant S, Timalsina U, Koirala S, Timalsina S, et al. Quality of life among people living with acquired immune deficiency syndrome receiving anti-retroviral therapy: a study from Nepal. HIVIAIDS (Auckland, NZ). 2013;5:277.

11. Huong AGW, Guan NC, Nordin ASA, Adlan ASA, Habil H. Quality of life assessment of opioid substance abusers on methadone maintenance therapy (MMT) in University Malaya Medical Centre. ASEAN Journal of Psychiatry. 2009;10(1):111.

12. Baharom N, Hassan MR, Ali N, Shah SA. Improvement of quality of life following 6 months of methadone maintenance therapy in Malaysia. Substance abuse treatment, prevention, and policy. 2012;7(1):32.

13. Torrens $M$, Domingo-Salvany A, Alonso J, Castillo C, San L. Methadone and quality of life. The Lancet. 1999;353(9158):1101.

14. Padaiga Ž, Subata E, Vanagas G. Outpatient methadone maintenance treatment program Quality of Life and health of opioid-dependent persons in Lithuania. Medicina. 2006;43(3):235.

15. Xiao L, Wu Z, Luo W, Wei X. Quality of life of outpatients in methadone maintenance treatment clinics. Journal of acquired immune deficiency syndromes (1999). 2010;53(Suppl 1):S116.

16. Ha NTT, editor The effect of methadone maintenance treatment in improvement of quality of life for heroin users in Hai Phong, Vietnam. The 4th International Conference on Reproductive Health and Social Sciences Research Bangkok, Thailand; 2010.

17. Ponizovsky AM, Grinshpoon A. Quality of life among heroin users on buprenorphine versus methadone maintenance. The American journal of drug and alcohol abuse. 2007;33(5):631-42.

18. Habrat B, Chmielewska $K$, Baran-Furga $H$, Keszycka B, Taracha E. Subjective Quality of Life in opiate-dependent patients before admission after six months and one-year participation in methadone program. Przeglad lekarski. 2002;59(4-5):351-4.

19. De Maeyer J, Vanderplasschen W, Broekaert E. Quality of life among opiate-dependent individuals: A review of the literature. International journal of drug policy. 2010;21(5):364-80. 